SP 083

1990
$\mathrm{ex} .2$

SP-2007.01262

ANAIS DA SOCIEDADE

\title{
ENTOMOLÓGICA DO BRASIL
}
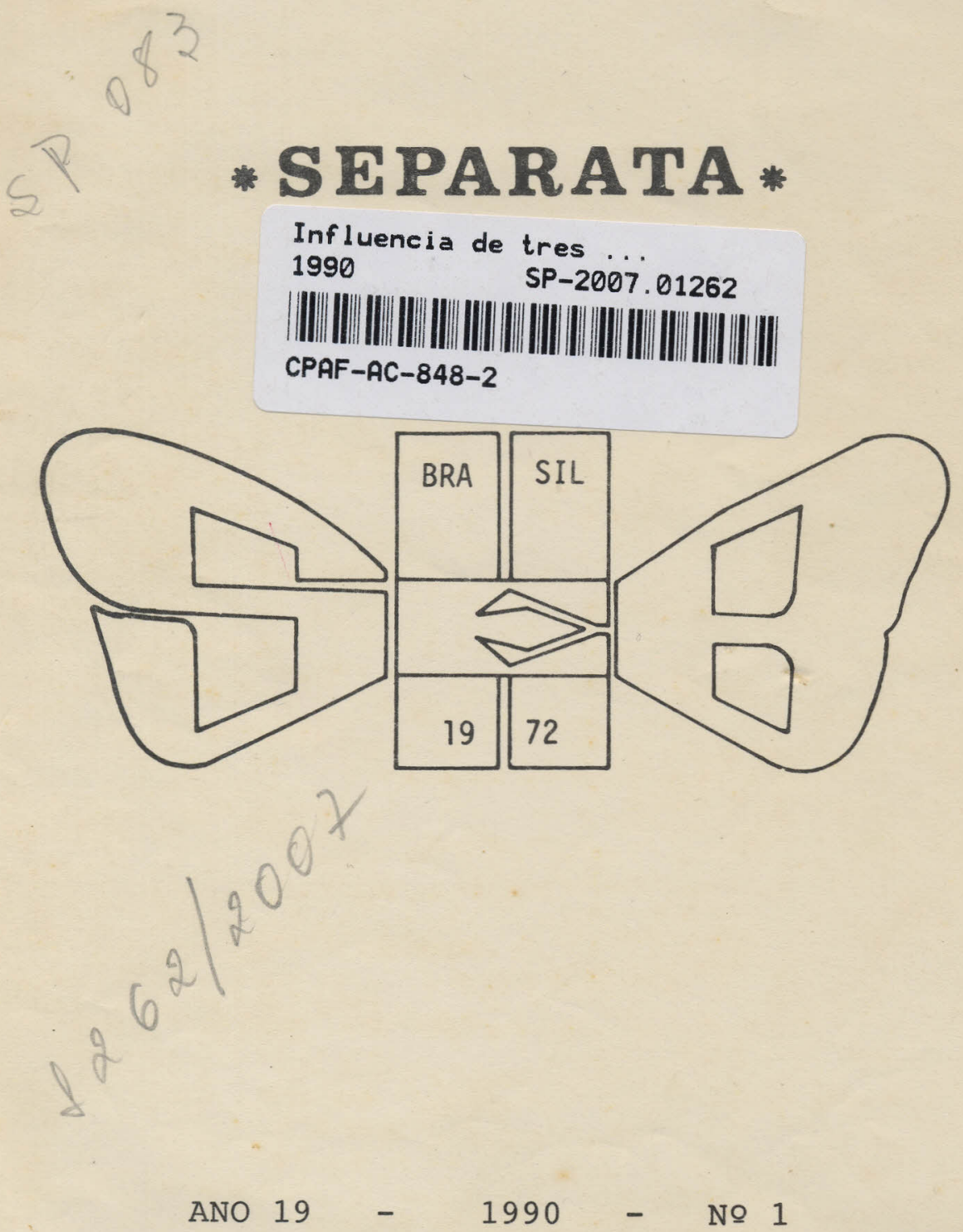


\title{
INFLUENCIA DE TRES INSETICIDAS SOBRE O CONTROLE E ATRATIVIDADE DE Cosmopolites sordidus (GERMAR, 1824) (COLEOPTERA, CURCULIONIDAE) EM ISCAS TIPO QUEIJO, NO MUNICIPIO DE RIO BRANCO (AC).
}

\author{
Murilo Fazolin ${ }^{1}$ Lair V. Pereira ${ }^{2}$ Carlos F. Wilcken ${ }^{3}$
}

\begin{abstract}
Influence of three insecticides on the control and atractivity of Cosmopolites sordidus (Germar, 1824) (Coleoptera, Curculionidae) to "cheese-type" baits in Northern Brazil.
\end{abstract}

Carbofuran ( $4 \mathrm{~g} / \mathrm{plant})$, Monocrotophos $(500 \mathrm{ml} / 1001)$ and Phosphamidon $(400 \mathrm{ml} / 1001)$ were applied on "cheese-type" baits in banana stalks (Var. Prata), to estimate the control and atractivity of Cosmopolites sordidus (Germar, 1824).

The pest was effectively controlled 8 to 10 weeks after application with all the products; no differences concerning mortality rates between them were observed. Phosphamidon showed a decrease in control efficiency after the first week from application and carbofuran adversely affected bait atractivity 8 weeks after application.

\section{RESUMO}

Com a finalidade de averiguar o controle e a atrativida de de Cosmopolites sordidus (Germar, 1824), através da utilização de carbofuran ( $4 \mathrm{~g} / \mathrm{planta})$, monocrotofós $(500 \mathrm{ml} / 100 \mathrm{l})$ e fosfamidom $(400 \mathrm{ml} / 100$ l) aplicados em iscas tipo "queijo" pro venientes de pseudocaules de bananeiras da variedade Prata,

Recebido em $26 / 9 / 89$

1 EMBRAPA/UEPAE de Rio Branco AC, Cx. Postal 392, 69900 Rio Branco AC.

2 Centro Nacional de Pesquisa da Seringueira e Dendē - EMBRAPA/CNPSD, 69000 Manaus, AM.

${ }^{3}$ Faculdade de Ciências Agronômicas - UNESP - Botucatu, SP. 
foi instalado um ensaio no município de Rio Branco (AC).

o controle efetivo da praga, independente do produto utilizado, foi constatado entre a 8 a e 10 a semanas após a aplicação, não havendo diferença entre eles quanto à mortalidade. Fosfamidon apresentou um decréscimo na eficiência de controle após a la semana de sua aplicação, e carbofuran influiu negativamente na atratividade das iscas após a 8 ạ semana.

\section{INTRODUCุÃO}

A cultura da banana no Estado do Acre vem se tornando ca da vez mais exigente na aplicação de tecnologias que visem aumento da produtividade, uma vez que seu consumo é tradicional na região, fazendo parte da dieta alimentar diária do acreano.

Nos últimos anos, embora tenha havido um aumento da área plantada com esta cultura, o acréscimo da produção esperado não correspondeu às expectativas. Vários aspectos agronômicos, em especial os fitossanitários, concorrem para o declínio da produtividade ou mesmo quase impossibilitam o cultivo de determinadas variedades de banana na região. Neste particular o moleque-da-bananeira Cosmopolites sordidus (Germar, 1824), é apontado como um dos responsáveis pela queda de produtividade, sendo am plamente disseminado e necessitando de um controle mais efe ivo. Alguns produtos vêm sendo testados, sendo que os organoclo rados foram relatados como mais eficientes que os fosforados e carbamatos (NOGUEIRA, 1976).

A resistência de $C$. sordidus aos clorados, bem como a desvantagem destes atingirem somente os adultos da praga, foram considerados nos trabalhos de MOREIRA (1979) e MELLO et al. (1979). Além disso, a proibição do uso destes produtos, pro piciou o início de pesquisas que apresentassem outra alternativa para esta finalidade. Assim, aldicarb, mefosfolan, paration, carbofuran, fensulfotion e dimetoato foram testados por MELLO et al. (1980), aplicando-os em pedaços de rizomas à disposição dos adultos da broca, observando uma sensibilidade dos insetos aos inseticidas.

Em aplicações por cobertura com fensulfotion, carbofuran e aldicarb nas dosagens de $80 \mathrm{~g}, 80 \mathrm{~g}$ e $40 \mathrm{~g} /$ cova respectivamente, ZEM et al. (1981) obtiveram resultados satisfatórios no controle de $C$. sordidus quando os tratamentos foram aplicados na época do plantio e repetidos 4 meses após.

CROCOMO et al. (1987) constataram que houve maior atratividade da isca tipo queijo em comparação com a do tipo "lurdinha", até o 150 día após a instalação do ensaio. Quando utilizaram, além da isca, aldicarb constataram que o maior número de insetos capturados ocorreu no tratamento com $0,300 \mathrm{~g}$ i.a. $/$ is ca. 
Pela carência de informações a respeito da atratividade e controle de $C$. sordidus na região produtora de banana de Rio Branco (AC), o objetivo do presente ensaio foi o de avaliar três inseticidas, disponíveis no mercado local, quanto a estes aspectos, utilizando iscas tipo queijo.

\section{MATERIAL E MÉTODOS}

o experimento foi instalado no sitio Colônia Tropical, situado no Município de Rio Branco (AC). O bananal tinha 12 anos de idade e era formado com a variedade Prata, sendo o espa çamento de $4 \times 4 \mathrm{~m}$ com 3 plantas por cova.

o delineamento experimental foi o de blocos ao acaso com 5 repetições, sendo cada uma representada por uma planta. Após a produção de frutos, cortou-se o pseudocaule na altura do rizoma, aplicou-se os inseticidas de cada tratamento, voltandose a depositar a parte cortada sobre a outra (isca tipo "queijo"). Os inseticidas testados foram carbofuran em grânulos ( $4 \mathrm{~g}$ /planta), monocrotofós (500 ml/100 l de solução) e fosfamidon (400 ml//100 l de solução). A aplicação dos grânulos foi reali zada diretamente sobre o pseudocaule seccionado e os insetici= das líquidos aplicados com o auxílio de uma seringa comum desprovida de agulha, depositando-se $5 \mathrm{ml} / \mathrm{sec} c ̧ a ̃ o$ de pseudocaule. Is cas não tratadas serviram de testemunha.

As avaliações foram realizadas semanalmente e consistiram da contagem do número de adultos de $C$. sordidus vivos e mor tos; neste último caso os individuos eram retirados da isca. Foi efetuado um total de 11 avaliações no período de $02 / 10 / 86$ à $26 / 12 / 86$.

Os dados foram transformados em $\sqrt{\mathrm{X}+0,5}$ e submetidos à análise de variāncia, sendo as médias de cada tratamento compa radas pelo teste de Tukey ao nivel de $5 \%$. Foi realizada, também uma análise de regressão polinomial para o número de indivíduos vivos e mortos e para a soma de ambos (atratividade).

\section{RESULTADOS E DISCUSSÃO}

\section{1 - Mortalidade de C. sordidus}

Não houve diferença significativa entre os inseticidas $\underline{u}$ tilizados quanto à mortalidade de adultos de $C$. sordidus, porém todos os produtos diferiram significativamente da testemunha (Quadro 1). A interação entre os inseticidas e as épocas de avaliação não foi significativa e a regressão polinomial entre - número de insetos mortos e a época de avaliação mostrou significância para uma curva de 40 grau. Sendo assim, dois picos de mortalidade de adultos foram obtidos: um na 2 a semana e ou- 
tro na 10 a semana após a aplicação dos inseticidas (Figura 1).

Esta variável não foi adequada para avaliar a ação dos inseticidas confirmando os resultados obtidos por CROCOMO et al. (1987) que consideram a possibilidade de a dosagem utilizada do produto permitir que haja uma locomoção do adulto para fora da isca após a intoxicação, obtendo-se desta ma neira um númerc subestimado de insetos mortos.

\section{2 - Número de adultos vivos de C. sordidus}

Não houve diferença significativa entre os inseticidas quanto ao número de adultos vivos presentes nas iscas, sendo este número reduzido e estatiticamente diferente da testemunha (Quadro 1). Houve significância na interação inseticidas $x$ épocas de avaliação, sendo que no desdobramento não houve diferença entre as sete primeiras avaliações, mas na $8 a, 9 a$ e $10 a$, - maior número de indivíduos vivos ocorreu na testemunha, diferindo significativamente dos tratamentos com inseticida, os quais não diferindo entre si. Na 11 a avaliação, a diferença entre o número de adultos vivos de todos os tratamentos voltou a ser não significativa, sugerindo que os inseticidas atuaram efetivamente entre a 8 a e 10 a semanas.

No desdobramento épocas de avaliação entre inseticidas, monocrotofos e carbofuran não diferiram significativamente en tre si e durante todo o período de avaliação mostraram umá tendência à uniformidade quanto ao número de indivíduos vivos presentes nas iscas tratadas. Já fosfamidon, na análise de regressão polinomial, apresentou significāncia para a reta, su gerindo que a maior eficiência do produto ocorreu na primeirá semana, decaindo a partir daí até a 11 a (Figura 2) .

A curva de 40 grau obtida para épocas de avaliação na testemunha, mostra dois picos distintos do número de indivíduos vivos: um na 2 a e outro na 10 a semana, sendo que de ordem de grandeza menores que a curva de 40 grau obtida em função do número de insetos vivos e a época de avaliação de todo o ensaio. Tal comportamento pode demonstrar que houve uma flutuação populacional natural da praga, e a diferença do número de individuos vivos entre as duas curvas pode representar o controle proporcionado pelos inseticidas (Figura 3).

\section{3 - Atratividade de adultos de C. sordidus}

Não houve diferença significativa entre as iscas trata das com inseticidas e a testemunha; porém quando se analisou separadamente as avaliações, encontrou-se diferenças na 8 a e 9 a contagem, sendo que neste caso, a testemunha mostrou-se sig nificativamente mais atrativa que as iscas tratadas com carbofuran; as tratadas com monocrotofos e fosfamidon apresentaram comportamento intermediário. Nas iscas tratadas com fosfamidon, houve, significância no estudo de regressão entre as épocas de avaliação e atratividade; obtendo-se uma reta, cujo 
sentido ascendente indicou que houve um aumento na atrativividade entre a 1a e 11a avaliação, sugerindo que, com o passar do tempo este inseticida, ao perder o efeito, aumentou a atratividade da isca (Figura 4).

A duração da atratividade das iscas, diferiu das relatadas por GALLO et al. (1988) e MELLO et al. (1979), de 14 e 30 dias respectivamente, uma vez que a atratividade máxima foi obtida na 10 a semana após a aplicação dos produtos (70 dias) (Figura 5).

\section{CONCLUSÕES}

Não houve diferença entre os três inseticidas quanto à mortalidade de $C$. sordidus.

Os inseticidas testados, em média, atuaram efetivamente no controle desta praga no periodo compreendido entre a 8 a $e$ 10 a semanas após o tratamento das iscas.

Fosfamidon apresentou maior eficiência de controle na primeira semana após a aplicação, decaindo linearmente até a 11 a semana.

A partir da 8 a semana, carbofuran influiu negativamente na atratividade das iscas sobre os adultos de $C$. sordidus.

QUADRO 1 - Número médio de adultos de C. sordidus mortos, vivos e atratividade de iscas tratadas com fosfamidon, carbofuran e monocrotofos.

\begin{tabular}{lccc}
\hline TRATAMENTOS & NO DE MORTOS & No DE VIVOS & ATRATIVIDADE \\
\hline Testemunha & $0,04 \mathrm{~b}$ & $1,05 \mathrm{a}$ & $1,12 \mathrm{a}$ \\
Fosfamidon & $0,40 \mathrm{a}$ & $0,50 \mathrm{~b}$ & $0,92 \mathrm{a}$ \\
Monocrotofos & $0,55 \mathrm{a}$ & $0,42 \mathrm{~b}$ & $1,07 \mathrm{a}$ \\
Carbofuran & $0,68 \mathrm{a}$ & $0,17 \mathrm{~b}$ & $0,91 \mathrm{a}$ \\
\hline
\end{tabular}

Mëdias seguidas de mesma letra, não diferiram significativamente pelo teste de Tukey ao nível de $5 \%$ de probabilidade. 


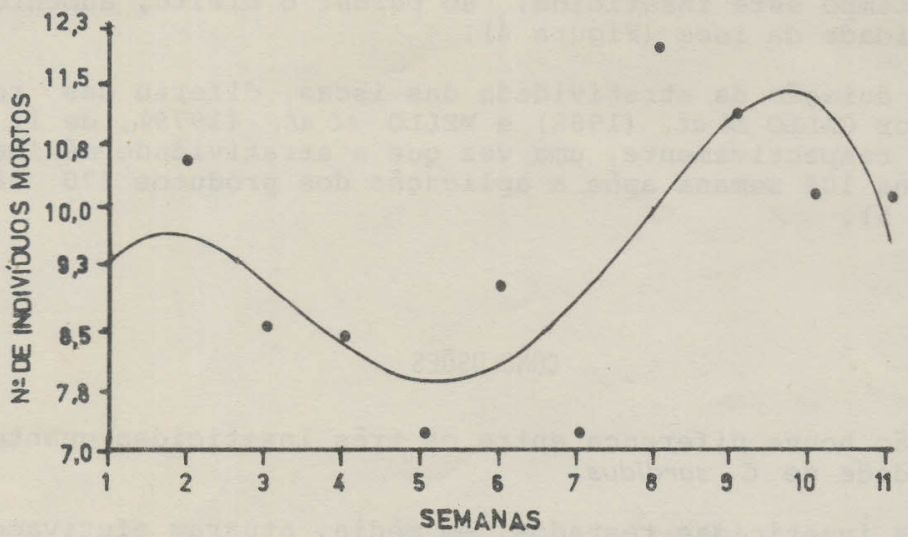

FIGURA 1 - Mortalidade média de adultos de $C$. sordidus em função das épocas de avaliação (semanas), apōs a aplicação dos inseticidas nas iscas.

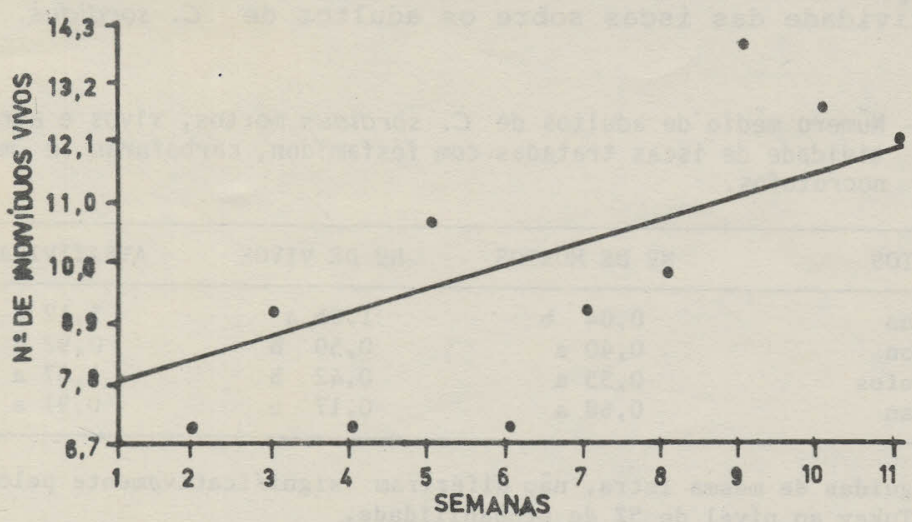

FIGURA 2 - Nümero de adultos de $C$. sordidus vivos em função das èpocas (semanas) dé avaliação, após a aplicação de fosfamidon nas iscas. 

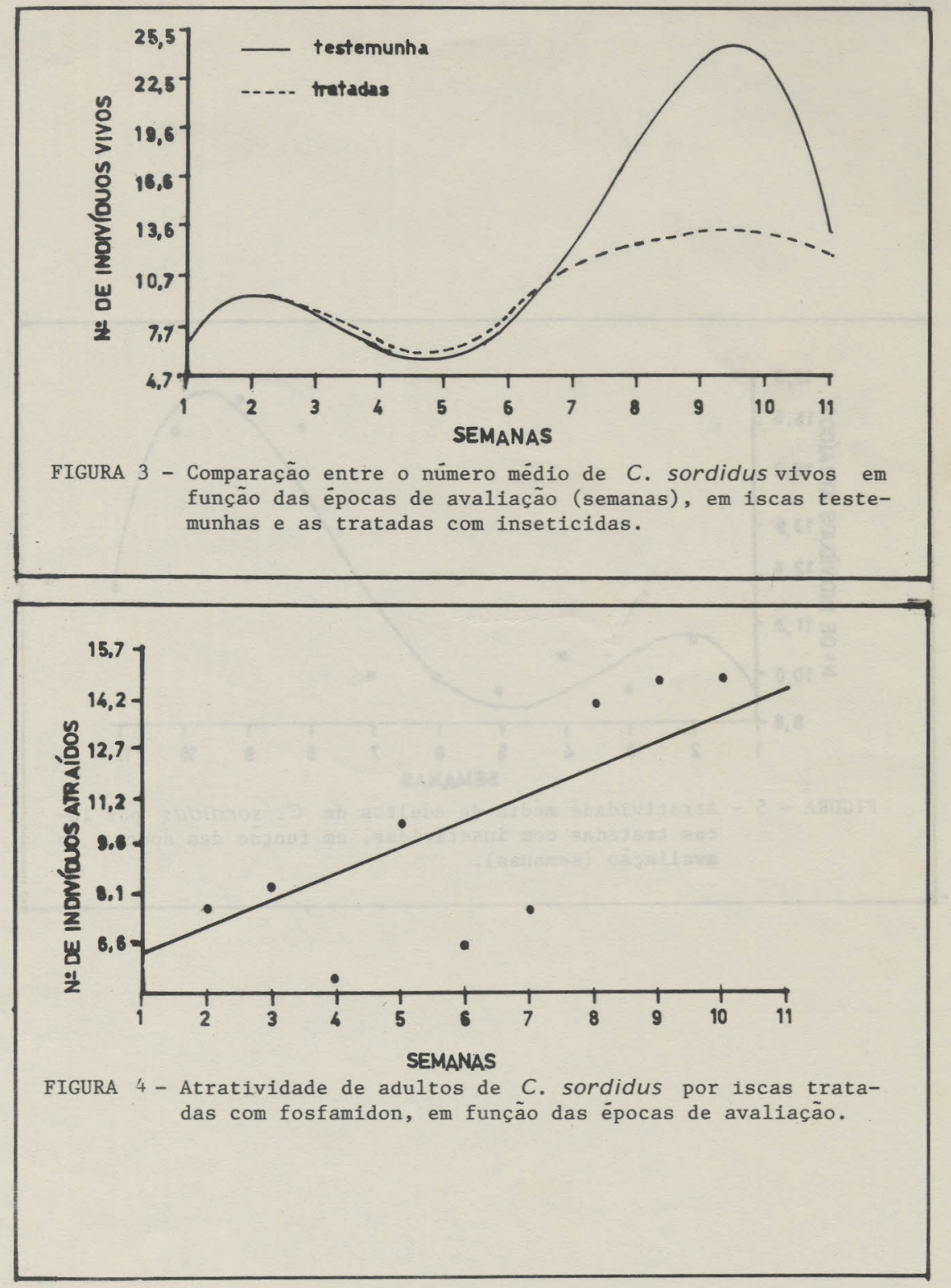


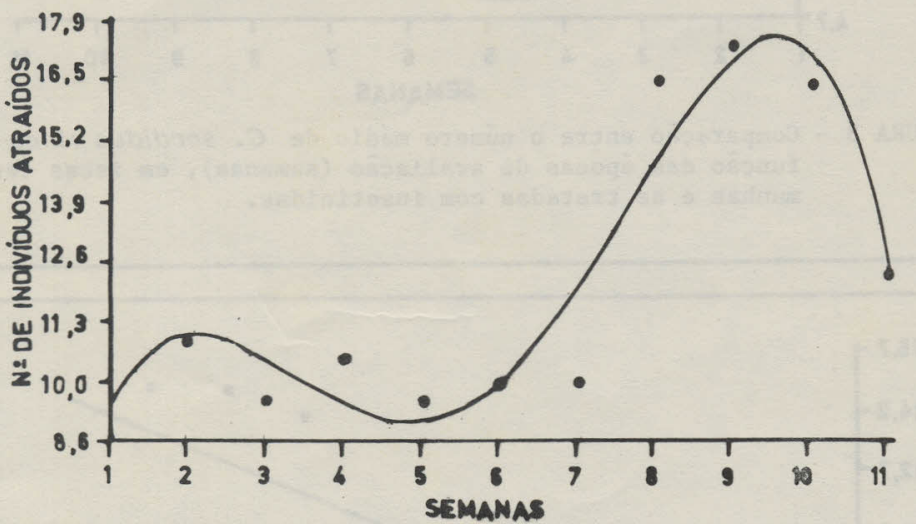

FIGURA - 5 - Atratividade média de adultos de $C$. sordidus por iscas tratadas com inseticidas, em função das épocas de avaliação (semanas). 


\section{LITERATURA CITADA}

CROCOMO, W.B.; GUASSU, C.M. de O.; ZAMBOM, S. Avaliação do efeito de inseticidas carbamatos sistêmicos sobre a atrati vidade de iscas para a broca da bananeira. Bolm Divulg. FEPAF Botucatu (3): 50-53, 1987.

GALLO, D.; NAKANO, O.; SILVEIRA NETO, S.; CARVALHO, R. P. L. ; BATISTA G.C. de; BERTI FILHO, E.; PARRA, J.R.P.; ZUCCHI, R. A.; ALVES, S.B.; VENDRAMIM, J.D. Manual de Entomologia Agrícola. 2 ed. São Paulo. Ed. Agronômica Ceres. 1988. 649p.

MELLO, E.J.R.; MELLO, R.H. de; SAMPAIO, A.S. Resistência ao aldrin em brocas de bananeira Cosmopolites sordidus no litoral paulista. Archos Inst. Biol. 45: 249-254, 1979.

MELLO, E.J.R.; MELLO, R.H. de; SUPLICY FILHO, N. Ensaios de laboratório para verificar a ação inseticida de granulados fosforados e carbamatos sobre brocas da bananeira resisten tes a aldrin. Biológico $46(7): 141-144,1980$.

MOREIRA, R.S. Combate à broca e aos nematóides da bananeira. Agronómico 33: 101-108, 1979.

NOGUEIRA, S.B. Efeito de alguns inseticidas, álcoois e ésteres aplicados em iscas contra as brocas da bananeira, Cos mopolites sordidus, Metamasius ensirostris e Metamasius inaequalis (Coleoptera: Curculionidae). In: CONBRESSO BRASILEIRO DE EN TOMOLOGIA, 3, Maceió, AL. 1976. p. 90-91. Resumos.

ZEM, A.C.; RODRIGUES, J.A.S.; ALVES, E.J. Eficiência de inse ticidas sistêmicos granulados no controle da broca da bananeira (Cosmopolites sordidus (Germar, 1824)) na cultivar Prata (Musa acuminata Simm \& Shep). Ecossistema 6(1): 52-55, 1981. 
